\title{
Redefining Groove
}

Deniz Duman ${ }^{1}$, Nerdinga Snape ${ }^{1}$, Petri Toiviainen ${ }^{1}$ and Geoff Luck ${ }^{1}$

${ }^{1}$ Department of Music, Art and Culture Studies, University of Jyväskylä

\begin{abstract}
Author Note
Deniz Duman https://orcid.org/0000-0002-1679-8550

Nerdinga Snape https://orcid.org/0000-0003-3196-0584

Petri Toiviainen https://orcid.org/0000-0001-6962-2957

Geoff Luck https://orcid.org/xxxx

We have no conflict of interest to disclose.

Correspondence concerning this article should be addressed to Deniz Duman, University of Jyväskylä, Musica, Building M, Room 319, Seminaarinkatu 15, 40014, Jyväskylä, Finland. Email: deniz.d.duman@jyu.fi
\end{abstract}




\begin{abstract}
Groove is a popular and widely-used concept in the field of music. Yet its precise definition remains elusive. Upon closer inspection, groove appears to be used as an umbrella term with various connotations depending on the musical era, the musical context, and the individual using the term. Our aim in this paper was to explore different definitions and connotations of the term groove so as to reach a more detailed understanding of it. Consequently, in an online survey, 88 participants provided free-text descriptions of the term groove. A thematic analysis revealed that participants' descriptions fit into three main categories: music-, experience-, and individual differences related aspects. Based upon this analysis, we propose a contemporary working definition of the term groove as used in the field of music psychology: "Groove is a participatory experience (related to immersion, movement, enjoyment, and social connection) resulting from subtle interaction of specific music- (such as time- and pitch-related features), performance- and/or individual differencerelated factors." Furthermore, we propose the terms perceived and induced groove to distinguish the different aspects of groove that are associated with its perceived musical features and induced effects on listeners. Importantly, this specification will permit further research with a common language to refer to distinct aspects of groove and thus create a more profound understanding in groove literature. Finally, we direct future studies to focus on the concept of groove under influence of different variables, such as the roles of individual differences (such as age, expertise and personality traits), execution of overt movements, or presences of others on listeners' perceived and induced groove experiences. These will further elucidate our understanding of what groove actually is.
\end{abstract}

Keywords: groove, thematic analysis, musical features, immersion, movement, positive affect, social connection 


\section{Introduction}

Groove is a popular term in the field of music. Yet, when attempting to define it, we find various meanings depending on the descriptor, the context, and the era. Some examples of the term groove used in a sentence refer to a state of being, a specific style of performance, or the music itself. For example, 'I am in the groove', 'this band plays groovy' or 'this song grooves'. In a recent work, Hosken (2020, p182) expressed the difficulty in describing the essence of groove as "like catching the water in a net".

Over time, groove has been linked with a diverse range of concepts. During the 1940s swing and jazz era, the phrase 'in the groove' was used to refer to a specific musical routine, preference, or style, indicating its aesthetic properties (Kernfeld, 2002). During the 1970s, groove was mostly associated with music genres such as funk and soul (Hale, 2014). Around the same time, groove was even used as a phrase to say something is 'cool' (Hein, 2011; Runyan et al., 2013; Dr. Scott Makeig, personal communication, November 18, 2019).

In addition to changing connotations over time, branches of musicology approach the term from different perspectives, too. From an ethnomusicological perspective, groove is defined as an "unspecifiable but ordered sense of something that is sustained in a distinctive, regular and attractive way, working to draw a listener in" (Feld, 1988, p.76). For music psychologists, who have conducted much groove-related work over the last couple of decades, groove has come to be defined rather more simply as a: 'pleasurable desire to move to music' (Kowalewski et al., 2020; Matthews et al., 2020; Lustig \& Tan, 2020; Senn et al., 2020; Haugen \& Danielsen, 2020). In order to demonstrate why this definition remains limited, we will review the principal literature on groove.

\section{Experiential and Musical Qualities of Groove}


Groove has been mostly attributed with experiences of movement (Janata et al., 2012; Stupacher et al., 2013; Ross et al., 2016; González-Sánchez et al., 2018, 2020) and positive affect (Madison, 2006; Kawase \& Eguchi, 2010; Janata et al., 2012; Witek et al., 2014). A recent study generated an Experience of Groove Questionnaire with two dimensions, 'pleasure' and 'urge to move' (Senn et al., 2020). Moreover, experience of flow is also often linked to the groove experience (Janata et al., 2012; Stupacher, 2019). Câmara and Danielsen (2018, p.2) describe groove as an ungraspable flow state: "Groove happens in the here-andnow of performance, meaning that groove is, in a sense, ungraspable as such - the very moment one tries to come to terms with a groove experience, one is no longer in the groove." Additionally, frequent exposure to musical styles as well as its schemas increases familiarity and is shown to create certain expectations which are found to predict groove ratings (Fitch, 2016; Senn et al., 2018). Pop and funk genres in particular were reported to induce a higher groove experience compared to rock music. However, groove is not only limited to popular music but also stated to be experienced in classical music (Frühauf et al., 2013). Therefore, one can argue that experience of groove is also tied with musical familiarity of the listener and personal music preferences. Expertise has been shown as another individual difference mediating groove experience (Senn et al., 2019; Witek et al., 2017).

In addition to experiential properties of groove, the literature suggests that the amount of felt groove can be modulated by varying musical features. Clear pulse and meter (Fitch, 2016), high event density (Madison et al., 2011; Senn et al., 2018), medium syncopation (Witek et al., 2014, 2017), tempo around 100-120 beats per minute (Etani et al., 2018), and low frequency range acoustic features (Stupacher et al., 2016; Hove, Martinez, \& Stupacher, 2019) are associated with experience of groove.

\section{Defining Groove}


The literature presented above on experiential and musical qualities that relate to groove reveals the diverse ways the term is conceptualized. Yet, often, groove descriptions remain limited. The common tendency is to refer groove solely as a 'pleasurable desire to move' or some other various, rather simple, attributions. For instance, groove is mentioned as a "primordial aspect of music" (Madison, 2001), a "state of listening" (Witek, 2009), a "sensation of movement" (Davies et al., 2012), or an "experience of music" that makes people dance (Madison et al., 2011; Madison, 2006; Stupacher et al., 2013). Elsewhere, groove is described as a feature that "works to draw a listener in" (Feld, 1988, p. 76), and that has affective impacts and connects the body, mind and music together (Witek, 2013). Groove is also associated with genres of North American and "Black Atlantic" music that emerged around the 1950s (Attas, 2011) such as jazz, funk, latin, reggae, and rock (Davies et al., 2012; Pressing, 2002; Frühauf et al., 2013). On the one hand, all these descriptors are relatable with the term, on the other hand it remains unclear what exactly one means by groove; whether it is a historical, musical or experiential phenomenon.

We are not the first musicologists to view groove as a multidimensional phenomenon. Frühauf and colleagues (2013) approached groove from its musical and performance perspective, highlighting its "dual nature" - a satisfying groove definition must contain a specific rhythmic structure as well as how that structure is performed. They elaborated that the experience of groove is constructed if musicians consciously modify microtiming by playing “in the pocket". More inclusively, Danielsen (2010) described the emergence of groove from the relationship between both the qualities of music and the listener experience. Similarly, Witek (2017, p.138) advanced groove phenomenologically as being "distributed between mind, body and music". Senn and colleagues (2020) reviewed various meanings that the term groove is being used by pointing out the nuances among 'a groove' (referring to a musical quality such as repetitive pattern in specific music genres), 'to groove' (denoting for 
an effortless and well-coordinated performance) and 'has groove' (indicating for pleasurableand movement-inducing music). These examples exhibit the concept of groove with its performance, music, and listener experience aspects.

Furthermore, this multidimensionality and lack of a comprehensive understanding of the term have resulted in rather dissimilar definitions of groove being used across different studies, leading to phenomenological ambiguity. For instance, music psychology studies tend to describe groove to participants mainly focusing on its movement aspect or some other studies use the term groove explicitly without referring to any particular dimension of it (for a review of different studies' working definitions of groove, see Senn et al., 2020). So, instead of studying groove as a whole, only a limited dimension of the term was often investigated, yet many continue referring to their investigation under the term groove. Such discrepancies in groove definitions not only lead to different conceptual understanding of the term by the participants of different studies, but also result in conclusions biased towards how the definition of groove was presented according to the specific field of the researcher.

Thus, the primary motivation for the study reported in this paper was to provide a more holistic representation of what exactly constitutes groove. We hypothesized that the term groove evokes various concepts other than pleasure or movement in participants. Using a free-text survey-based approach, our goal was to provide a more comprehensive working definition of groove that would encompass multiple groove-related dimensions that have arisen in previous work. 


\section{Method}

\section{Procedure}

The research reported here formed part of an extensive online listening survey which was conducted to investigate a range of factors influencing people's groove experiences. The survey was distributed on webropol.com via personal social media accounts and the University's emailing lists. Initially, participants were informed about the content of the survey, their rights as a participant, and were requested to state their written consents to participate. Participation and data processing were kept anonymous. Completing the entire survey took about 45 minutes, and participants had a chance to win a $50 €$ voucher upon completion.

\section{Materials}

As part of this particular study, the last section of the online survey, data about participants' self-evaluated groove familiarity and free-text groove descriptions were analyzed. All participants rated their familiarity with the term groove on a 7-point Likert scale. Subsequently, they were asked to respond to the question "what makes a song 'groove' in your opinion" as a free-text, on a voluntary based.

\section{Participants}

One hundred and five participants (61 women, 41 men, 3 other) aged 16 to 54 $(M=27.07, S D=6.46)$ completed the entire survey. Participants originated from 19 different countries, with the majority of them reporting to be Finnish $(N=56)$ or Turkish $(N=23)$ nationals. Fifty-nine of the participants were students. On average, participants reported 2.86 hours of music listening per day $(S D=1.90)$ and 1.85 hours of dancing per week $(S D=2.21)$. 
Moreover, three levels of musical training were observed among the participants: Eight years and above $(N=29, M=15.73, S D=5,16)$, less than 8 years $(N=35, M=3.41, S D=2.14)$, and no musical training $(N=41)$. Twenty-four of the participants received on average 3.69 years of dance training $(S D=2.18)$. Of the 105 participants, 88 provided free-text groove descriptions.

\section{Analysis}

Two of the authors involved in an abductive thematic analysis. Since the aim of this research was to review definitions of groove with a more holistic approach, a mixed data analysis method, abduction was preferred. Abduction is stated as "a creative inferential process aimed at producing new hypotheses and theories based on surprising research evidence" (Timmermans \&Tavory, 2012, p.167). Within the methods of qualitative research, the thematic analysis was chosen since it is argued as "foundational method" of qualitative research that focuses on identification of recurring patterns (themes) by affording "flexibility" for the researchers (Braun \&Clarke, 2006). Therefore, thematic analysis provided possibility to perform this mixed method, abductive, analysis. As described by Timmermans and Tavory (2012, p.171), “Abduction suggested explanations, which were then formalized into deductions, while induction confirmed them through empirical testing.”, in this way both theory- and data-led analyses could provide a detailed analysis of participants' free-text groove descriptions. For the analysis, while the first author familiarized herself with the data and generated initial codes with a theory-led, deductive approach, the second author investigated the data with a data-led, inductive approach. Later, the codes generated by these authors discussed and a mutual agreement with categorization of the concepts was reached. As a final step, data was investigated one more time in order to make sure the established categories do not leave out any further insides. Overall, a coding schema considering the six phases of thematic analysis (1- familiarizing with data, 2-initial coding, 3- looking for 
themes, 4- revisiting themes, 5- naming themes, and 6- reporting) described by Braun and Clarke (2006) was followed. 


\section{Results}

\section{Groove Familiarity Ratings}

Mean groove familiarity score was $4.6(S D=1.868)$, indicating that participants were somewhat familiar with the term. Participants were divided into three categories according to their familiarity ratings; ratings of 7-6 formed the high $(N=39), 5-4$ the $\operatorname{mid}(N=35)$ and 3-2-1 the low $(N=32)$ groove familiarity levels. Participants with 8 years and above musical training reported higher groove familiarity $(M=5.24, S D=1.5)$ compared with participants with less than 8 years $(M=4.49, S D=2.06)$ and no music training $(M=4.16, S D=1.5)$. An analysis of variance test revealed no significant difference of groove familiarity as a function of reported musicianship. Interestingly, four participants with more than 8 years of music training reported their groove familiarity as low.

\section{Groove Descriptions}

The total word count across all groove descriptions was 2348. Frequencies of the most commonly used words are presented in Table 1. All words were first simplified to their basic forms, language mistakes were corrected, then articles, pronouns, and prepositions were removed from the list. Words occurring at least 8 times are presented in the table.

Despite the survey's explicit inquiry (the question asked being "what makes a song 'groove' in your opinion”), participants still provided definitions of groove broader than only what is derived from the music itself. For example, there were definitions related to participants' own experiences as well as how groove emerges by the virtue of certain elements of a performance. As a consequence, we categorized various aspects of groove, as presented in the next section. 
Table 1. Frequencies of the most commonly used words.

\begin{tabular}{|c|c|}
\hline Frequency & Word \\
\hline 44 & groove \\
\hline 43 & rhythm \\
\hline 43 & song \\
\hline 30 & make \\
\hline 29 & move \\
\hline 25 & bass \\
\hline 25 & music \\
\hline 22 & beat \\
\hline 19 & want \\
\hline 15 & melody \\
\hline 14 & feel \\
\hline 14 & good \\
\hline 14 & time \\
\hline 12 & drum \\
\hline 12 & instrument \\
\hline 11 & dance \\
\hline 10 & clear \\
\hline 10 & create \\
\hline 10 & guitar \\
\hline 9 & flow \\
\hline 9 & like \\
\hline 9 & tempo \\
\hline 9 & well \\
\hline 8 & catchy \\
\hline 8 & element \\
\hline 8 & line \\
\hline 8 & nice \\
\hline
\end{tabular}

\section{Categories Defining Groove}

Participants' groove descriptions revealed details about performance, music-, experience-, and individual differences-related aspects of groove. Therefore, these details were grouped under (1) musical, (2) experiential, and (3) individual differences aspects categories of groove, which can be found with their associated subcategories in Table 2. 
Table 2. Main and subcategories of participants' groove descriptions.

\begin{tabular}{|c|c|}
\hline Main Categories & Subcategories \\
\hline \multirow[t]{12}{*}{ 1. Musical Aspect } & 1.1. Performance \\
\hline & 1.1.1. Artists \\
\hline & 1.1.2. Instruments \\
\hline & 1.1.3. Styles \\
\hline & 1.2. Music-Related Features \\
\hline & 1.2.1. Time-Related Features \\
\hline & Rhythm \\
\hline & Beat \\
\hline & Tempo \\
\hline & 1.2.2. Pitch-Related Features \\
\hline & Melody \\
\hline & Frequency Range \\
\hline
\end{tabular}

2. Experiential Aspect

2.1. Immersion

2.2. Movement

2.3. Positive Affect

2.4. Social Connection

3. Individual Differences 3.1. Musical Preferences

3.2. Current Mood

\section{Musical Aspect}

The musical aspect includes both performance and music-related features subcategories. The performance subcategory covers producers of groove (artists), musical instruments that are used during a groove-related performance, and musical styles associated with groove. The music-related features subcategory consists of time- and pitch-related features. 
1.1. Performance A musical performance associated with groove was described as being skillfully performed by artists. In other words, 'performance ability of the players' contributes to production of groove. P9 exemplified how a drummer's performance is relatable with groove:

“A great drummer can make a single symbol 'swing', which can give a groove for a whole song."

The most commonly mentioned instruments related with groove were bass and drums, followed by guitars, wind instruments, and vocals. Especially 'bass guitar and drums' instrument pair were associated with groove. Their function was suggested to produce a "good" rhythm and a basis for other instruments. Moreover, harmonious interplay of instruments was often commented upon. As P105 said:

"A song with a groove has a clear and funky bass line, some wind instruments, usually a saxophone and two trumpets. Then add some percussions and all these playing well together."

Related with performance aspects, several musical styles were mentioned in participants' groove descriptions. Funk and jazz were the most frequently observed musical styles, followed by metal (this finding will be elaborated on in the discussion section.) While some participants mentioned groove existing in various music styles, one associated groove with 'funk and disco' and one other with 'jazz and blues'. For example:

"There can be many different kinds of great grooves that can be found in different music styles." (P9)

"I usually connect groove to songs that are or have funk or disco elements." (P82)

"I associate 'groove' with jazzy-bluesy type of music.” (P98) 
1.2. Music-Related Features This subcategory contains musical features associated with groove, namely as time- and pitch-related features. Similar to the 'harmonious interplay of musical instruments', a delicate interaction between musical features was remarked upon as another factor in groove related music. For example, P19 suggested groove as an interaction between rhythm and melody:

"It is a mix of rhythm and melody that work well together. Many times, a clear melody over more complex rhythm or beat, or a simple beat with a more complex melody."

Certain timing variations in music such as using a steady beat as well as rhythmic complexity such as use of half notes or syncopation were linked with groove. Related to timerelated features of groove, the most commonly emerging codes (rhythm, beat, and tempo) were further investigated. In response to the inquiry of the survey 'what makes a song groove', numerous responses used rhythm as a primary descriptor for groove. Beat was the other temporal musical feature associated with groove. Groove description of P30 demonstrated this temporal aspect, specifically explaining how production of rhythm and beat contributes to groove:

"Groove is mostly rhythmic feel that a song or a band has. [...] Groove is not about getting everything perfectly on time and on the beat, but it is more like getting things in the right place related to the beat. For example, sometimes bass player has to play a little bit before the beat (maybe in jazz context) and sometimes a little bit behind the beat." Tempo was also mentioned in relation to groove. It was observed that groove might exist at different tempi, with some participants indicated their preference for slow whereas others for fast tempo. P79, for example, remarked:

"I often prefer slower tempos that feel 'heavy' but faster tempos can also be 'groovy'."

Pitch-related features of music were also often mentioned by participants. Particularly, a separation between high and low frequency ranges was noted. This separation might be 
further linked with bass and drum instruments creating a rhythm-related basis for the other instruments, as they often carry low frequency range acoustic features. For higher frequencies, on the other hand, a few participants mentioned the function of melody to add a flavor to the song. The following descriptions demonstrated the role of pitch-related features on groove:

"Drums and bass create the foundation for it in a band and other instruments support it."

"A lot of groovy genres also have a separation in the range of instruments and voices. The bass is heavy and solid, and higher instruments sort of sparkle over the top." (P29)

The above-mentioned musical variations that relate to groove might be further associated with establishing certain 'musical expectations' in the listeners. These expectations were derived from the adjectives that appeared frequently in participants' groove descriptions. Some of these adjectives that were linked with the musical aspect of groove and listener expectations were: clear, predictable, consistent, stable, steady and simple; whereas other adjectives demonstrated the function of violation of expectations such as unexpected and sudden. Involvement of such musical expectations might bring people closer to music, make them engage with it more deeply. As a result, the above-mentioned musical variables induce certain psychological and physical states (engagement or participatory experiences) in the listeners and impact their groove experiences. (These experiences will be elaborated in the next category.) Moreover, while describing their groove experiences, participants used certain keywords that revealed their 'engagement' with music. For example, participants used adjectives like catchy, interesting, complex, intense, heavy, bonding and synchronizing; verbs such as make, create, want, keep, emerge, capture and drive; nouns like feel, weight, ambiguity, attention and flavor. These keywords demonstrate how music associated with 
groove makes listeners engage with it. The groove description by P10 exemplifies these findings:

"It has a clear rhythm so that it is easy to dance to it, but it can't be too predictable. The song also needs to have good energy and funny/clever/interesting lyrics. I'd say that if a song puts you in a good mood, has attitude and makes you want to move or sing, that song is groovy."

The description of groove by P29 further describes how the musical aspect of groove connects to its experiential aspect:

"Musically it's about slightly thwarting timing expectations, leaning back on the beat but always getting where you need to be. There's a naive physics to it; groove sounds heavier and stronger than other rhythms, but the momentum of it drives you to the next beat at the same time as holding you back, creating this sense of movement and weight that works well with some kinds of dancing [...] makes it fun to both dance and sing to."

\section{Experiential Aspect}

The features of groove described thus far, which establish musical expectations and engagement, might be further interpreted as a bridge between the music and the listener. They invite the listener to participate and experience the music on a deeper level. These experiences might be seen as levels of engagement or participatory experiences with music which are described as immersion, movement, positive affect, and social connection.

2.1. Immersion Beyond finding groove-related music as interesting and engaging, participants often mentioned being in an immersed state with music while describing their groove experiences. By immersed state, we primarily refer to an 'experienced connection with music'. Qualities of such connections with music are various and observed from the 
following descriptions, which are also related with concepts of "flow" (elaborated in the discussion section), time and space:

"when you understand and get into the flow of the song" (P33)

"feel the song and feel that you are a part of it" (P78)

"something that hooks me" (P3)

"some kind of catchiness" (P6)

"feeling different from the present" (P56)

"it gives the listeners space and allows them to be immersed in the song" (P36)

Moreover, these descriptions of connection with music are further linked with physical and psychological approximation of music which can be related to the movement and positive affect subcategories, such as in the following examples:

"It has to do with song having the ability to immerse you in it in an embodied way."

"It captures you to it's rhythm, makes you want to move along." (P97)

"Dig deep into the music and enjoy." (P31)

Other qualities of this connection with music can be described as 'perceived motion', 'perceived emotion' and 'perceived meaning' in music. Several participants associated groove with motion- and affect-related qualities of music. Examples of references to perceived motion-related qualities include:

"there is perpetual motion in the song" (P36)

"playing a moving, funky tone" (P43)

and of affect-related qualities:

“nice happy melody” (P86)

In addition to perceived motion- and emotion-related features of music, several participants referred to lyrical aspects of music. However, lyrics do not appear to be a 
prerequisite for experiencing groove. Rather, lyrics seem to play a subsidiary role. It was suggested that the function of lyrics was to help the listener to connect with the song. Thus, lyrical elements of music, which might be interpreted as 'perceived meaning' in music, make it easy for listeners to connect with the music and contribute to their groove experience as P67 stated:

"The lyrics has a big contribution to it since the words make it easier to connect with the song."

Even though all of these perceived qualities are related with music itself, yet these percepts are part of listener's individual experiences. Moreover, like in the example of "happy melody", 'happy' denotes for a perceived quality of the music, rather than an induced emotional state on the listener. (Examples to the induced effects of groove on listeners can be found in the next subheadings.) Therefore, we propose a distinction between perceived qualities of music and music's induced effects on the listeners, in the context of groove. (This distinction will be elaborated in the discussion section.)

2.2. Movement Movement-related responses were the most frequently reported experiences in participants' groove descriptions. Different than perceived motion related aspect that help listeners to connect with music and experience groove, this subcategory covers the induced experiences; which cover both the 'psychological experiences towards movement' (such as desire to move and sense of movement) and 'bodily experiences of movement' (such as dancing, nodding, swaying, singing, and jamming). Furthermore, this movement aspect was often mentioned as a 'drive' rather than a quality that the listener consciously acts towards; as P16 described:

“A song that make your hips move even if your brain don't want to." 
2.3. Positive Affect Positive affect was the second frequently observed groove experience in participants' responses. Here are some of the examples how participants described their induced positive emotional experiences associated with groove:

"It has to do with enjoyment." (P48)

"It needs to have a good feel to it. I mean it doesn't have to be happy, but it needs to have that something." (P13)

"A sudden change to 'half time feel' can be very satisfying, because there is a release for the built-up 'tension' of the fast parts.” (P79)

2.4. Social Connection In addition to feeling an immersive state to music and experiencing it in relation with movement and positive affect; a final subcategory, experience of social connection, emerged from the data. This subcategory has a social aspect which is linked with experiencing affinity towards the performers of the music and/or the other people who share the same atmosphere with the listener. Instances for this induced experience of social connection with the performer and other people were described as:

"Something I feel through the artists. For example, I feel the groove in a Jazz band." $(\mathrm{P} 42)$

"Bonding you to the people who are also grooving at the same time." (P29)

\section{Individual Differences}

Thusfar we presented various experiences of listeners associated with groove. The experiences of feeling immersed with music, movement, positive affect and social connection appear to be affected by individual differences. Our data provided evidence for two subcategories of individual differences, musical preferences and the current state of the listeners appear to play a role in their groove experiences. 
3.1. Musical Preferences Listeners' musical acquaintanceships and listening habits, which also relate to their familiarity with music, shape their musical preferences. Participant responses which reflect features related with their musical preferences and groove are gathered in this subcategory. Such musical preferences were derived from descriptions when participants associated groove with their favorite music, referenced to their genre preferences or gave musical examples of the artists that they listened to. Artists which appeared in groove descriptions either as participants' associations with groove or their musical preferences are: ABBA, Lamb of God, Pantera, Jamiroquai, Childish Gambio, Lady Gaga, Hozier, Christina Aguilera, Kool \& the Gang, and Earth, Wind and Fire. Associated era and the musical styles of these artists are various; leading us to the consideration of groove as an individual and personal experience regardless of the kind or time period of the music. Moreover, the groove description by P13 exhibits how musical exposure (familiarity) might linked with groove experience:

"It helps if I am at least somewhat familiar with the song."

3.2. Current Mood As it was overviewed earlier that experience of groove induces positive affect, the current emotional state of the listener also seem to influence experiencing groove in a song. According to P47, to experience groove, music should match with the current emotional state:

"If a song expresses your emotions and emphasizes them, then song groove."

In Figure 1, we demonstrated how the musical aspect of groove relates to its experiential qualities which are mediated by individual differences; these subcategories are interrelated with each other by their nature. In terms of musical aspect of groove (presented in blue), the music itself cannot be separated from its performance aspect. It is the artists of music who 
play the musical instruments that give rise to production of certain musical features which are then associated with specific musical styles. These musical styles then become part of listeners' personal music preferences or the listeners might prefer to listen to a certain type of music depending on their current mood. These individual differences (presented in green) influence people's groove experiences. The subcategories of experiential aspect (presented in red) should also be considered in relation to each other. By creating certain musical expectations, listeners engage with music which give rise to psycho-physical participatory experiences. In other words, embodiment of music is closely linked with an immersed state with music which is further associated with experiences of positive affect and desire to move to music which then lead to a feeling of social connection with the others in the same environment. These steps can further be seen as levels of engagement (or participatory experiences) with music, shape the listener's current mood and determine the degree of experienced groove. 


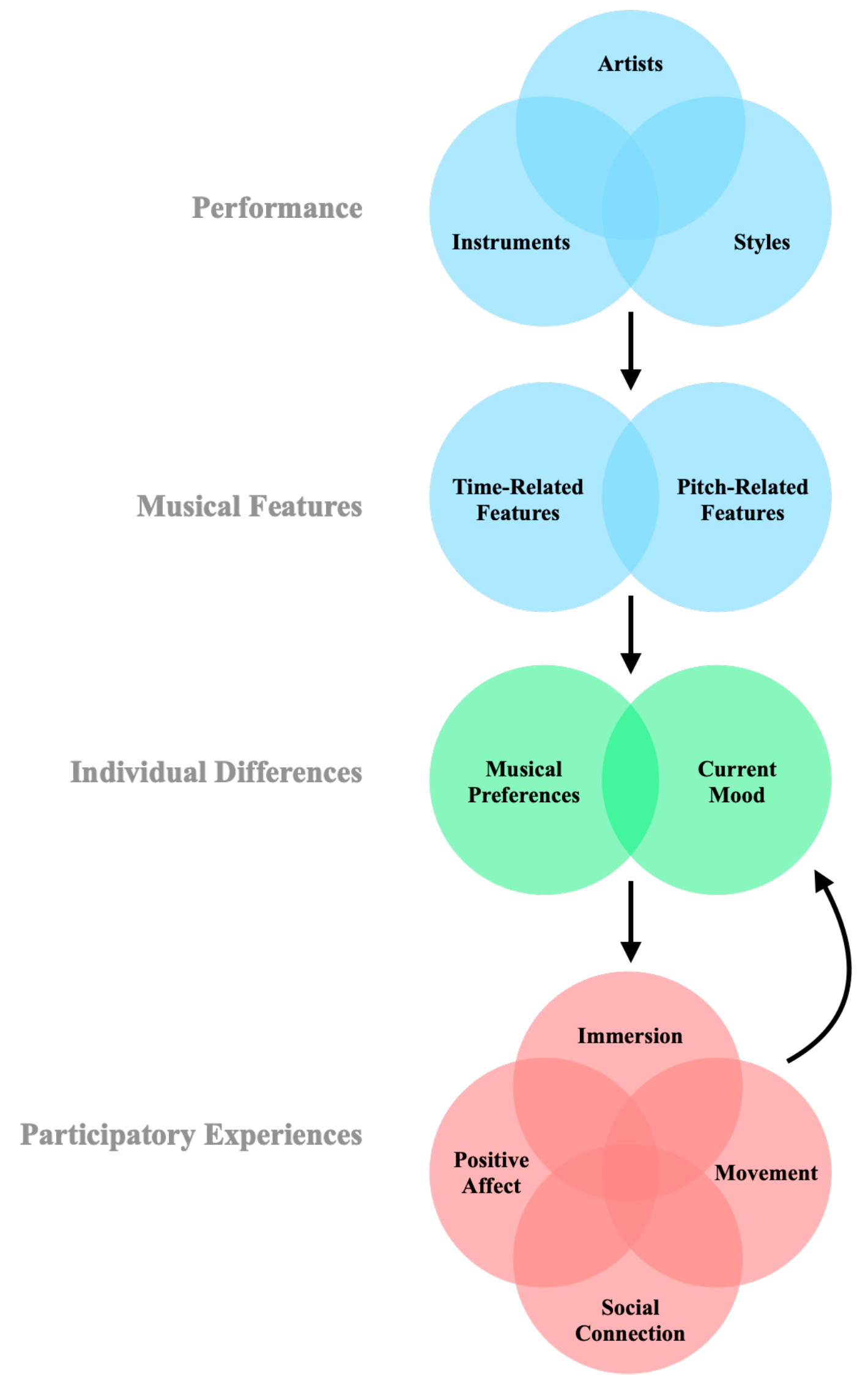

Figure 1. A model for categories of participants' groove descriptions demonstrates the relationship between musical (blue) and experiential (red) aspects of groove, which is shaped also by individual differences (green). 


\section{Discussion}

In this paper, we initially reviewed pertinent aspects of the groove literature, with a particular focus on how the term groove - with its numerous connotations - has been defined. Subsequently, we presented a new thematic analysis of groove descriptions which highlighted three main dimensions of the concept: 1) musical (performance and musical features), 2) experiential, and 3) individual difference-related. In line with previous research, these categories depict groove as a multifaceted phenomenon (Hosken, 2020; Stupacher et al., 2016). Specifically, we observed this multidimensionality from participants' groove descriptions: In people's minds, groove evokes the concepts associated with music itself and how music is performed, and experiences of the music by its listeners in relation to both their present and prior experiences. Moreover, despite explicitly asking in our survey "what makes a song 'groove' in your opinion?", participants' definitions referred not only to the music itself but also their own particular listening experiences as well as the way the music was performed. This highlights the multidimensional nature of groove, and how the notion of groove is driven not only from the musical piece, but how it's also significantly related both to one's personal experiences as well as how the music is communicated by its players.

Although groove evokes certain semantic associations in people's minds, the ambiguity surrounding its description may emerge because of its multifaceted and complex character. Groove is not a simple concept, but one that arises from various interactions between a) the artists who are performing the music, (b) the musical elements that emerge during the performance, (c) its listeners and the artists, (d) the listeners as individuals, and (e) the listeners within a group. Thus, the elements creating the groove experience might not be easily formulated. Instead, elements that create groove are interwoven. In other words, it can be said that a specific performance of music shapes peoples' personal groove experiences. 
Compared to the previous literature on groove, our findings revealed groove to be both a musical (e.g., rhythm-related, Senn et al., 2018) and experiential (e.g., creating a pleasurable desire to move, Janata et al., 2012) phenomenon. Additionally, in order to represent the concept of groove comprehensively, with the groove model in Figure 1, we suggested a link between individual groove experiences with musical aspect of groove. Moreover, our data provided evidence for groove-related experience of immersion with music. This immersive state with music might be interpreted as a flow state associated with groove. Previously, Stupacher (2019) reported that a flow state correlated with experience of groove in a tapping experiment. However, the terms flow and immersion are not necessarily entirely interchangeable. Agreval and colleagues (2019) propose that states of flow and immersion differ depending on the activity one is engaged in having passive or active involvement. Unlike the experimental method that was used by Stupacher (2019), since our focus was primarily on listener's groove definitions (which do not necessarily involve active engagement), we preferred to use the term immersion instead of flow.

In addition to an immersive state, we proposed a social connection characteristic of groove in light of participants' groove descriptions. Shared activities such as music listening and making, dance and coordinated movements, as well as shared emotions are shown to be closely linked with establishing social identity, bonding and connection (Savage et al., 2020; Marsh et al., 2009; Lee et al., 2020; Arewasikporn et al., 2019). Additionally, people feel affinity towards others who share similar musical preferences with them (Boer et al., 2011). Although these shared experiences, which are closely related to a sense of social connection, are also related to groove, research examining groove experiences in relation to social connection is scarce. A recent motion capture study reported increased groove ratings, movement energy, and interpersonal connection when participants were able to access social cues (eyes open versus eyes closed) (Dotov, Bosnyak, \& Trainor, 2021). Witek (2017, p.149) 
proposes that groove disables boundaries between the music, mind and body, enabling its listeners to "feel at one" with music and others in the same environment:

"Collectively filling the gaps in syncopation draws many bodies into the same space, in which bodies are distributed and the boundaries between different agents are further blurred. [...] The open spaces in syncopated groove become portals through which people can share the same mental, temporal and physical dimensions."

Witek further describes syncopation (a contributor to musical groove) as affording 'social entrainment' in which temporal, psychological, and physical experiences of people are exchanged within the group. In light of these findings, it would be worth investigating further how experience of groove is linked to social cues.

\section{A Complementary Definition of Groove}

Due to the evolving nature of groove over its history, as reviewed earlier, definitions of groove remain ambiguous or confusing. Using categories derived from our thematic analysis, we hereby propose a more contemporary and complementary working definition of groove in the field of music psychology: "Groove is a participatory experience [related to immersion, movement, enjoyment, and social connection] resulting from subtle interaction of specific music- [such as time- and pitch-related features], performance- and/or individual differences-related factors." We suggest that future research empirically tests the role of these different elements in the context of groove.

Importantly, this proposed groove definition as 'participatory experience' was observed in our data, such as in how participants described groove as something they experienced via an urge to be 'involved in' physically and/or psychologically. With a similar view, Keil (1995, p.2) talks about "participatory discrepancies" (PD): "PDs exist. Between players. Between the beginnings of their notes. In the moment when each of us chooses to 
snap fingers, or nod a head, or in the instant when many decide to get up and dance because the music is so contagious". These participatory discrepancies, interpreted as a contagious function of music, might extend the concept of groove as an invitation to 'join', or, as Witek (2017) states, "filling in the gaps". If not with instruments, with one's own body. In this way, groove induces participatory experiences in listeners in the form of an immersive state towards the music, a desire to move, an induction of positive affect, or a feeling of social connection. This notion of an automatic and unconscious process in which one embodies or becomes 'one' with (or through) music (and thus with the group that the listener is surrounded by) requires further research to re-evaluate the origins of groove. By conceptualizing groove as a multifaceted phenomenon with participatory qualities that cover both the production and the experience of music, one might view groove as originating from the very earliest musical activities of humankind.

\section{Distinction between Perceived and Induced Groove}

In the process of formulating our definition of groove, we became aware of the importance of distinguishing between perceived and induced groove. One might conceptualize this in much the same way as in the music and emotion literature (for a review, see: Juslin \& Laukka, 2004). Perceived groove is associated with musical features, while induced groove refers to effects it induces in listeners. Perceived groove can be seen as an equivalent of the musical aspect of groove, relating to both perceived qualities of the musical performance and the derived musical features. Induced groove refers to the experiential aspect of groove which relates to induced effects of music, namely as the experiences of an immersive state, movement, positive affect and social connection. Clearer reference to these distinct aspects of groove could enable a common language to run through future research, leading to a more profound understanding of groove in the literature. 


\section{Limitations and Future Directions}

When developing our definition of groove, our aim was to capture multiple facets of the term. However, it should be noted that our sample mainly consisted of young students from Finland, and their groove descriptions might be naturally biased towards their own understanding of the term. The fact that our sample was skewed towards younger people also made it impossible to make comparisons between different age groups. In addition to comparing groove definitions between different age groups, people from different expertise groups, especially musicians, as previous research has done (Senn et al., 2019; Witek et al., 2017), might reveal more nuanced understanding of perceived and induced groove. Other measures of individual difference that could be considered include personality, capacity for empathy, and daily music listening habits. We suggest that future research focus in more detail on such interpersonal influences on the experience of groove.

Finally, since groove was reported to invite listeners to become 'one' or 'participate in', such as by inducing the urge to move to the music, the experience of groove might also be considered a dynamic state. In other words, there might be differences in induced groove experiences depending on whether the listener experiences the music only by passive listening or actively participates through movements and dance. The presence of others during the experience should also be considered. The when and how of listeners' experiences of and attitudes towards groove thus requires further investigation, and could even offer new insights not only into the foundations of groove, but also shed light on the origins of dance and music. 


\section{References}

Arewasikporn, A., Sturgeon, J. A., \& Zautra, A. J. (2019). Sharing positive experiences boosts resilient thinking: Everyday benefits of social connection and positive emotion in a community sample. American journal of community psychology, 63(1-2), 110 121.

Agreval, S., Simon, A., Bech, S., Bærentsen, K. B., \& Forchammer, S. (2019). Defining immersion: Literature review and implications for research on immersive audiovisual experiences. In AES 147th Convention (p. 10275). Audio Engineering Society.

Attas, R. E. S. (2011). Meter as process in groove-based popular music (Doctoral dissertation). University of British Columbia.

Braun, V., \& Clarke, V. (2006). Using thematic analysis in psychology. Qualitative research in psychology, 3(2), 77-101.

Boer, D., Fischer, R., Strack, M., Bond, M. H., Lo, E., \& Lam, J. (2011). How shared preferences in music create bonds between people: Values as the missing link. Personality and Social Psychology Bulletin, 37(9), 1159-1171.

Câmara, G. S., \& Danielsen, A. (2018). Groove. In A. Rehding \& S. Rings (Eds.), The Oxford handbook of critical concepts in music theory. Oxford: Oxford University Press.

Danielsen, A. (Ed.). (2010). Musical rhythm in the age of digital reproduction. Ashgate Publishing, Ltd.

Davies, M., Madison, G., Silva, P., \& Gouyon, F. (2012). The effect of microtiming deviations on the perception of groove in short rhythms. Music Perception: An Interdisciplinary Journal, 30(5), 497-510. https://doi.org/10.1525/mp.2013.30.5.497 
Dotov, D., Bosnyak, D., \& Trainor, L. J. (2021). Collective music listening: Movement energy is enhanced by groove and visual social cues. Quarterly Journal of Experimental Psychology. https://doi.org/10.1177/1747021821991793

Etani, T., Marui, A., Kawase, S., \& Keller, P. E. (2018). Optimal tempo for groove: Its relation to directions of body movement and Japanese nori. Frontiers in psychology, 9, 462. https://dx.doi.org/10.3389\%2Ffpsyg.2018.00462

Feld, S. (1988). Aesthetics as iconicity of style, or'Lift-up-over Sounding': Getting into the Kaluli groove. Yearbook for Traditional Music, 20, 74-113. https://doi.org/10.2307/768167

Fitch, W. (2016). Dance, music, meter and groove: a forgotten partnership. Frontiers in Human Neuroscience, 10, 64. https://doi.org/10.3389/fnhum.2016.00064

Frühauf, J., Kopiez, R., \& Platz, F. (2013). Music on the timing grid: The influence of microtiming on the perceived groove quality of a simple drum pattern performance. Musicae Scientiae, 17(2), 246-260. https://doi.org/10.1177\%2F1029864913486793

González- Sánchez, V. E., Żelechowska, A., \& Jensenius, A. R. (2018). Correspondences between music and involuntary human micromotion during standstill. Frontiers in psychology, 9, 1382. https://doi.org/10.3389/fpsyg.2018.01382

González- Sánchez, V. E., Żelechowska, A., \& Jensenius, A. R. (2020). Analysis of the movement-inducing effects of music through the fractality of head sway during standstill. Journal of motor behavior, 52(6), 734-749. https://doi.org/10.1080/00222895.2019.1689909

Hale, J. (Director). (2014). The Story of Funk: One Nation Under a Groove [Motion picture]. BBC. 
Haugen, M. R., \& Danielsen, A. (2020). Effect of tempo on relative note durations in a performed samba groove. Journal of New Music Research, 1-13. https://doi.org/10.1080/09298215.2020.1767655

Hein, E. (2011, December 1). How did the word "groovy" come to acquire its current meaning? [Web log post]. Retrieved January 10, 2021, from http://www.ethanhein.com/wp/2011/how-did-the-word-groovy-come-to-acquire-its current-meaning/

Hosken, F. (2020). The subjective, human experience of groove: a phenomenological investigation. Psychology of Music, 48(2), 182-198. https://doi.org/10.1177\%2F0305735618792440

Hove, M. J., Martinez, S. A., \& Stupacher, J. (2019). Feel the bass: Music presented to tactile and auditory modalities increases aesthetic appreciation and body movement. Journal of Experimental Psychology: General. https://doi.org/10.1037/xge0000708

Janata, P., Tomic, S. T., \& Haberman, J. M. (2012). Sensorimotor coupling in music and the psychology of the groove. Journal of Experimental Psychology: General, 141(1), 54. https://doi.org/10.1037/a0024208

Juslin, P. N., \& Laukka, P. (2004). Expression, perception, and induction of musical emotions: A review and a questionnaire study of everyday listening. Journal of new music research, 33(3), 217-238. https://doi.org/10.1080/0929821042000317813

Kawase, S., \& Eguchi, K. (2010). The concepts and acoustical characteristics of 'groove' in Japan. PopScriptum 11-The Groove Issue, 1-45.

Keil, C. (1995). The theory of participatory discrepancies: A progress report. Ethnomusicology, 39(1), 1-19.

Kernfeld, B. (2002). Groove (i). The New Grove Dictionary of Jazz, 2. 
Kowalewski, D. A., Kratzer, T. M., \& Friedman, R. S. (2020). Social Music: Investigating the Link Between Personal Liking and Perceived Groove. Music Perception, 37(4), 339-346. https://doi.org/10.1525/mp.2020.37.4.339

Lee, H., Launay, J., \& Stewart, L. (2020). Signals through music and dance: Perceived social bonds and formidability on collective movement. Acta Psychologica, 208, 103093.

Lustig, E., \& Tan, I. (2020). All about that bass: Audio filters on basslines determine groove and liking in electronic dance music. Psychology of Music, 48(6), 861-875. https://doi.org/10.1177\%2F0305735619836275

Madison, G. (2001). Different kinds of groove in jazz and dance music as indicated by listeners' ratings [Proceedings]. VII International Symposium on Systematic and Comparative Musicology and III International Conference on Cognitive Musicology, Jyväskylä, Finland. http://urn.kb.se/resolve?urn=urn:nbn:se:uu:diva-38816

Madison, G. (2006). Experiencing groove induced by music: consistency and phenomenology. Music Perception, 24(2), 201-208. https://psycnet.apa.org/doi/10.1525/mp.2006.24.2.201

Madison, G., Gouyon, F., Ullén, F., \& Hörnström, K. (2011). Modeling the tendency for music to induce movement in humans: First correlations with low-level audio descriptors across music genres. Journal of experimental psychology: human perception and performance, 37(5), 1578. https://doi.org/10.1037/a0024323

Marsh, K. L., Richardson, M. J., \& Schmidt, R. C. (2009). Social connection through joint action and interpersonal coordination. Topics in Cognitive Science, 1(2), 320-339.

Matthews, T. E., Witek, M. A., Lund, T., Vuust, P., \& Penhune, V. B. (2020). The sensation of groove engages motor and reward networks. NeuroImage, 116768. https://doi.org/10.1016/j.neuroimage.2020.116768 
Pressing, J. (2002). Black Atlantic rhythm: Its computational and transcultural foundations. Music Perception, 19(3), 285-310. https://doi.org/10.1525/mp.2002.19.3.285

Ross, J. M., Warlaumont, A. S., Abney, D. H., Rigoli, L. M., \& Balasubramaniam, R. (2016). Influence of musical groove on postural sway. Journal of Experimental Psychology: Human Perception and Performance, 42(3), 308. https://doi.org/10.1037/xhp0000198

Runyan, R. C., Noh, M., \& Mosier, J. (2013). What is cool? Operationalizing the Construct in an Apparel Context. Journal of Fashion Marketing and Management: An International Journal. https://doi.org/10.1108/JFMM-01-2012-0001

Savage, P. E., Loui, P., Tarr, B., Schachner, A., Glowacki, L., Mithen, S., \& Fitch, W. T. (2020). Music as a coevolved system for social bonding. Behavioral and Brain Sciences, 1-36.

Senn, O., Bechtold, T. A., Hoesl, F., \& Kilchenmann, L. (2019). Taste and familiarity affect the experience of groove in popular music. Musicae Scientiae, 1029864919839172. https://doi.org/10.1177\%2F1029864919839172

Senn, O., Bechtold, T., Rose, D., Câmara, G. S., Düvel, N., Jerjen, R., Kilchenmann, L., Hoesl, F., Baldassarre, A., \& Alessandri, E. (2020). Experience of Groove Questionnaire: Instrument Development and Initial Validation. Music Perception: An Interdisciplinary Journal, 38(1), 46-65. https://doi.org/10.1525/mp.2020.38.1.46

Senn, O., Kilchenmann, L., Bechtold, T., \& Hoesl, F. (2018). Groove in drum patterns as a function of both rhythmic properties and listeners' attitudes. PloS one, 13(6), e0199604. https://doi.org/10.1371/journal.pone.0199604

Stupacher, J. (2019). The experience of flow during sensorimotor synchronization to musical rhythms. Musicae Scientiae, 23(3), 348-361. https://doi.org/10.1177\%2F1029864919836720 
Stupacher, J., Hove, M. J., \& Janata, P. (2016). Audio features underlying perceived groove and sensorimotor synchronization in music. Music Perception: An Interdisciplinary Journal, 33(5), 571-589. https://doi.org/10.1525/mp.2016.33.5.571

Stupacher, J., Hove, M. J., Novembre, G., Schütz-Bosbach, S., \& Keller, P. E. (2013). Musical groove modulates motor cortex excitability: a TMS investigation. Brain and cognition, 82(2), 127-136. https://doi.org/10.1016/j.bandc.2013.03.003

Timmermans, S., \& Tavory, I. (2012). Theory construction in qualitative research: From grounded theory to abductive analysis. Sociological theory, 30(3), 167-186.

Witek, M. (2009). Groove experience: Emotional and physiological responses to groove based music [Proceedings]. 7th Triennial Conference of European Society for the Cognitive Sciences of Music (ESCOM 2009), Jyväskylä, Finland. https://jyx.jyu.fi/handle/123456789/20923

Witek, M. A. (2013). '... and I feel good!'The relationship between body-movement, pleasure and groove in music (Doctoral dissertation). Oxford University, UK.

Witek, M. A. (2017). Filling in: Syncopation, pleasure and distributed embodiment in groove. Music Analysis, 36(1), 138-160.

Witek, M. A., Clarke, E. F., Wallentin, M., Kringelbach, M. L., \& Vuust, P. (2014). Syncopation, body-movement and pleasure in groove music. PloS one, 9(4), e94446. https://doi.org/10.1371/journal.pone.0094446

Witek, M. A., Popescu, T., Clarke, E. F., Hansen, M., Konvalinka, I., Kringelbach, M. L., \& Vuust, P. (2017). Syncopation affects free body-movement in musical groove. Experimental Brain Research, 235(4), 995-1005. https://doi.org/10.1007/s00221-016-4855-6 